\title{
Adherence to antiretroviral therapy in Nigeria: an overview of research studies and implications for policy and practice
}

This article was published in the following Dove Press journal:

HIVIAIDS - Research and Palliative Care

27 March 2010

Number of times this article has been viewed

\author{
Emmanuel Monjok' \\ Andrea Smesny' \\ Ita B Okokon ${ }^{2}$ \\ Osaro Mgbere ${ }^{3}$ \\ E James Essien' \\ 'Institute of Community Health, \\ University of Houston, Texas Medical \\ Center, Houston Texas 77030, USA; \\ ${ }^{2}$ Department of Family Medicine, \\ University of Calabar Teaching \\ Hospital, Calabar, Nigeria; ${ }^{3}$ Bureau \\ of Epidemiology, Houston Department \\ of Health and Human Services, \\ Houston, Texas 77054, USA
}

Correspondence: Emmanuel Monjok Institute of Community Health, Texas Medical Center, I44I Moursund Street, Suite II 19 , Houston, Texas 77030 , USA

$\mathrm{Tel}+7 \mid 37958321$

$\mathrm{Fax}+7137958383$

Email emonjok@uh.edu

\begin{abstract}
Both Human Immunodeficiency Virus (HIV) infection and AIDS remain major public health crises in Nigeria, a country which harbors more people living with HIV/AIDS than any country in the world, with the exception of South Africa and India. In response to the HIV pandemic, global and international health initiatives have targeted several countries, including Nigeria, for the expansion of antiretroviral therapy (ART) programs for the increasing number of affected patients. The success of these expanded ART initiatives depends on the treated individual's continual adherence to antiretroviral (ARV) drugs. Thirteen peer-reviewed studies concerning adherence to ART in Nigeria were reviewed with very few pediatric and adolescent studies being found. Methodologies of adherence measurement were analyzed and reasons for nonadherence were identified in the geopolitical zones in the federal republic of Nigeria. The results of the literature review indicate that adherence to ART is mixed (both high and low adherence) with patient self-recall identified as the common method of assessment. The most common reasons identified for patient nonadherence include the cost of therapy (even when the drugs are heavily subsidized), medication side effects, nonavailability of ARV drugs, and the stigma of taking the drugs. This manuscript highlights the policy and practice implications from these studies and provides recommendations for future ART program management.
\end{abstract}

Keywords: adherence, antiretroviral therapy (ART), HIV, PLWHA, Nigeria

\section{Introduction}

The human immunodeficiency virus (HIV) pandemic continues to spread in the population making HIV disease one of the most important public health crises in the world. In 2007, there were approximately 33 million people globally living with HIV, with two million deaths attributed to HIV/AIDS and three million new infections occurring annually. ${ }^{1}$ Sub-Saharan Africa harbors about $67 \%$ of the total worldwide infected population with Nigeria having the third largest infected population ( 2 to 3.2 million) of people living with HIV/AIDS (PLWHA) in the world after South Africa and India. ${ }^{1}$

Global health initiatives such as the United States (US) President's Emergency Program for AIDS Relief (PEPFAR) and the Global Fund to fight AIDS, Tuberculosis and Malaria (GFTAM) have responded to the HIV pandemic by expanding the provision of ART to the increasing number of affected patients. ${ }^{1}$ This has resulted in the expansion of treatment and prevention programs that have increased ART access to previously un-served and underserved populations. Nigeria is one of the target countries for these international programs and is also a country with strong local political support for these initiatives. 
Antiretroviral (ARV) drugs have to be taken as a lifelong therapy and their success relies on continual adherence to the medication regimen. A rate of adherence of approximately $90 \%-95 \%$ is required to avoid rapid development of drug resistance and treatment failure. ${ }^{2,3}$ Large scale adherence studies have been conducted in African countries demonstrating mixed results on patient faithfulness to $\mathrm{ART}^{4}{ }^{4}$ With the rapid increase in patient access to ART in Nigeria, it has become vital to continuously monitor treatment adherence and identify interventions that can encourage its sustainability.

This retrospective literature review specifically focuses on patient adherence to ART from the beginning of Nigeria's ART program in 2002 to the end of November 2009. Results from research studies specifically measuring patient adherence to highly active ARV drugs are summarized and possible structural, sociocultural and/or economic problems, as well as other factors that may have affected ART adherence in Nigeria, are identified. In addition, certain issues regarding ART programs which are specific to Nigeria and should be taken into consideration when modifying these programs' policies and practice are also identified.

\section{Adherence to combination antiretroviral therapy}

Treatment adherence is defined as the extent to which a person currently takes prescribed medication. It is widely agreed that in order to achieve an undetectable viral load and prevent the development of drug resistance, a person on ARV drugs needs to take at least $95 \%$ of the prescribed doses on time. ${ }^{5}$

There is no gold standard to measure adherence. Commonly used methods include patient self-report, pill counts, pharmacy refill records, drug level monitoring, electronic drug monitoring, and physician assessment, each of which has advantages and disadvantages. ${ }^{4}$ The most commonly used method in resource-limited settings is selfreport or pharmacy refill records. ${ }^{5}$

Adherence has been shown to be a major predictor of viral suppression of HIV replication, ${ }^{6}$ emergence of ART drug resistance, ${ }^{7}$ disease progressions,${ }^{8}$ and death..${ }^{9} 10$ Adherence monitoring and evaluation of ART are, therefore, essential public health surveillance tools in the prevention of HIV in high, middle, and low income countries.

\section{Barriers to adherence}

Systematic reviews ${ }^{11,12}$ have indicated that the most important and frequent factors that negatively impact adherence in developing countries are cost, stigma, alcohol abuse, and structural barriers such as lack of transportation and pharmacy stock-outs.

An analysis of the barriers that affect adherence should be viewed as a dynamic interaction of biologic and social factors. ${ }^{13}$ The main biosocial variables needed to understand nonadherence can be defined within eight categories: socioeconomic factors, health care system factors, social capital, cultural methods of health and disease, personal characteristics, psychological factors, clinical factors, and antiretroviral regimen. ${ }^{13}$ Based on this framework, addressing adherence may require providing social support to patients, lowering or eliminating user fees, bringing health care workers closer to the patients, improving drug procurement strategies and/or creating mechanisms for lowering the cost of drugs and laboratory tests. ${ }^{13}$

In other settings, addressing adherence may require investing in and improving primary health care, public hospital and referral networks or recruiting and retaining human resources. ${ }^{13}$ An understanding of the complex interplay of the biosocial factors is necessary to understand nonadherence, which can help in guiding the designs of more effective nonadherence intervention programs. ${ }^{13}$

\section{The Nigerian ART program}

The Federal Government of Nigeria initiated the national ARV program in January 2002 as part of an expanded response to care and support for PLWHA. Under this program, 10,000 adults and 5000 children were treated with a 3-drug ARV combination; 2 NRTI (lamivudine + stavudine) and 1 NNRT (nevirapine). The program began in February 2002 involving 25 treatment centers across the 6 geopolitical zones of the country and was subsidized at a cost of US\$ 10 a month for each patient. ${ }^{14}$

Unfortunately, in 2004 the program suffered a major setback when it was hit by a shortage of the US\$ 3.5 million worth of drugs imported from India. During this time, many patients were off drugs for up to 3 months, which created a structurally-induced nonadherence problem in the national ARV drug program. Eventually, the program was resumed when another US\$ 3.8 million worth of drugs was ordered and received.

Another program was started in 2006 with the goal of providing ARV drugs at no cost to about 250,000 HIV-positive patients. Although a total of 74 treatment sites were participating in this program by the end of $2006,{ }^{15}$ only about $15 \%$ of PLWHA needing ARV drugs in Nigeria had access to this treatment. ${ }^{16}$ 


\section{Materials and methods}

An electronic search of published literature was conducted using the search terms 'adherence', 'antiretroviral therapy', and 'Nigeria'. PubMed ${ }^{\circledR}$, ISI Web of Science ${ }^{\circledR}$ Science Citation Index ${ }^{\circledR}$, PloS Medicine, and all indexed journals on HIV/AIDS that addressed adherence to ART in Nigeria from 2002 to 2009 were searched. Websites of international organizations, international conferences on all aspects of HIV/AIDS, and private research HIV/AIDS foundations were also explored and an Internet Google ${ }^{\circledR}$ search using the same terms was also completed. A total of twenty one articles addressing adherence to ART in Nigeria were identified. Thirteen peer-reviewed articles were included in this review and eight conference abstracts were excluded. The search was restricted to English language articles only.

\section{Results}

A summary of the thirteen identified research studies measuring adherence to ART in Nigeria is shown in Table 1. All the data collected for these studies came from HIV patients who were receiving ARV drugs through international initiatives as well as the national government program. The Table includes the health facility and the geopolitical zone where each study was conducted, the method of adherence assessment and measurement, and the reasons for nonadherence.

\section{Study characteristics and adherence measurements}

Study characteristics concerning adherence to treatment showed mixed results with some showing low adherence ${ }^{14,17,18,20-23,25,26}$ and others showing high adherence. ${ }^{19,22,24,27,28}$ One study ${ }^{19}$ used direct observation of ART using both community providers and family members and compared adherence with those patients who self-administered their drugs. Only one pediatric adherence study was indentified ${ }^{24}$ All other study populations were adult HIV patients within the age range of 35-40 years. One study ${ }^{22}$ compared adherence in fasting and nonfasting HIV patients during the Ramadan period. Only one study ${ }^{17}$ utilized the services of community health extension workers to followup on patients who missed monthly clinic appointments. Another study ${ }^{20}$ incorporated focus group discussions and ethnographic analysis to compare adherence from two treatment centers and to show how cost-of-treatment could be a determinant factor in adherence.

All of the studies reviewed used patient self-recall to assess adherence. Two studies ${ }^{18,23}$ combined patient recall with the pharmacy refill method and in three studies ${ }^{14,19,22}$ patient recall was matched with estimation of biologic markers, viral load, and CD4 cell count. These matched studies showed that the biologic markers correlated well with adherence, increased CD 4 cell count, and reduced viral load in patients with $>95 \%$ adherence to ART.

\section{Reasons for nonadherence}

Cost to the patient for medication, adverse side effects, nonavailability of drugs, and social stigma were the major reasons reported for patient nonadherence and were common to all studies reviewed. Forgetfulness on the part of the patient and in the case of children (mothers or caregivers) was a recurring reason for noncompliance. In addition, pill overload was also mentioned as a factor affecting adherence in two of the studies. ${ }^{21,25}$ The study that utilized directly observed treatment methodology using community support showed a much greater adherence rate when compared to those studies where patients administered their own medications. ${ }^{19}$

\section{Discussion}

The level of adherence to drug therapy has been reported to affect the outcome of treatment in the patients on ARV drugs. While good adherence results are effective in reducing viral loads and restoring a patient's immune system, nonadherence often leads to treatment failure. ${ }^{6-9}$ Studies conducted in both developed and developing countries ${ }^{11,12}$ have shown that adherence in developing countries is often equal to or higher than that in developed countries, ${ }^{11,12,29}$ but there is now research evidence that this may wane over time. ${ }^{29}$ The reason for these better adherence outcomes in sub-Saharan Africa has been attributed to the phenomenon of social capital. ${ }^{30}$

Patient self-report was the most commonly method of adherence measurement used in the studies. This method has proven reliable since the estimation of CD4 count and viral load in some of the studies ${ }^{14}$ correlated well with the high adherence to drug therapy achieved. Drug level monitoring and electronic drug monitoring methods of measurement are not commonly used in adherence studies in developing countries because they are expensive, technically difficult, and require laboratory testing and training of personnel. Even studies in advanced countries in North America and Europe where these methods are utilized more often, studies still show a large dependence on patient self-recall. ${ }^{4}$

The most prevalent factor and major barrier to adherence in all of the studies examined was cost. Although the ARV drugs are heavily subsidized in the Nigerian program, patients have to bear the cost of transportation to and from the health 


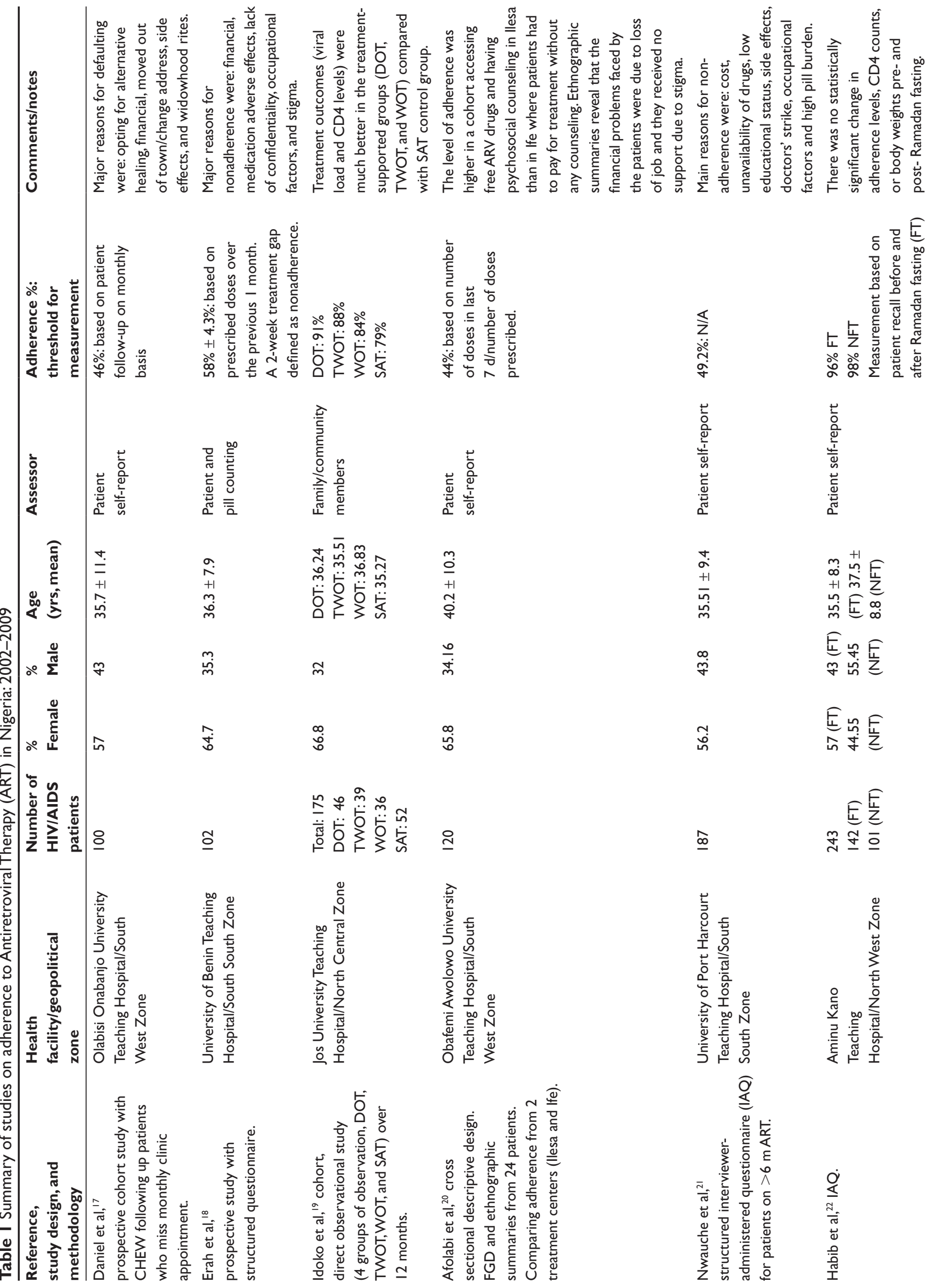




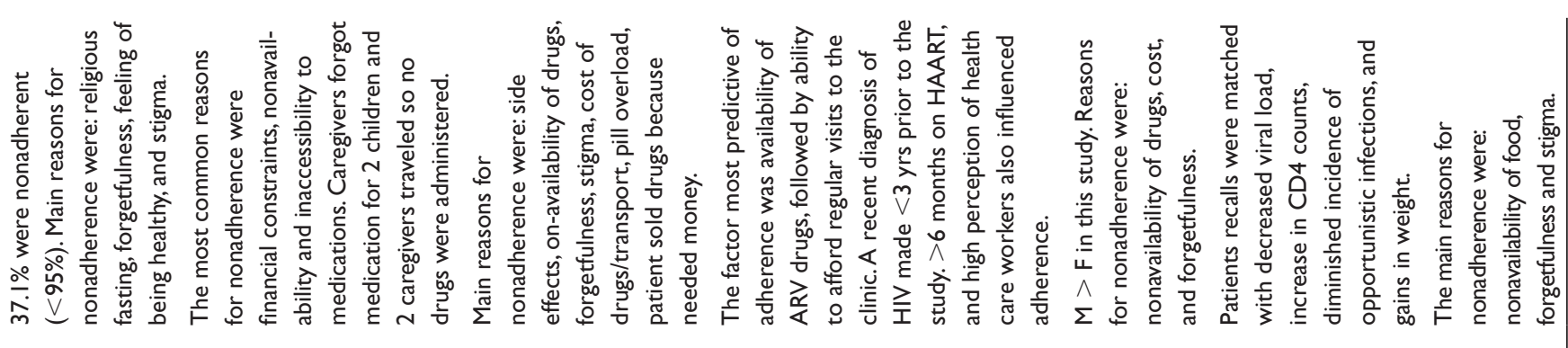
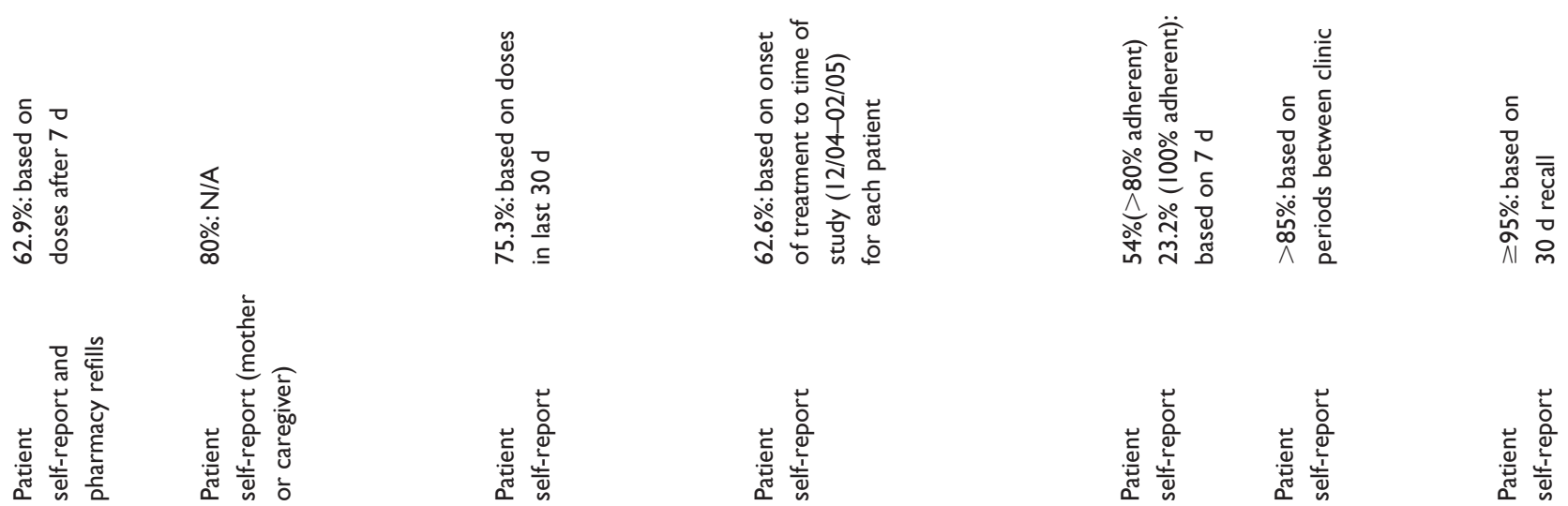

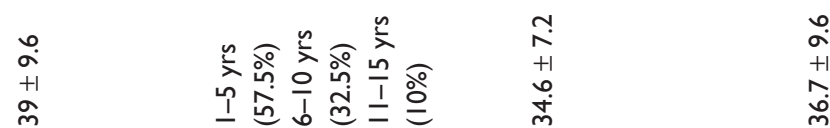

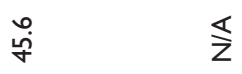

$\stackrel{n}{\stackrel{n}{m}}$

$\stackrel{m}{m}$
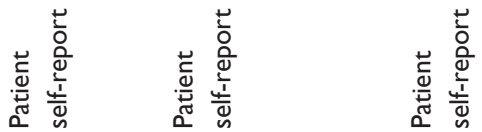

过点

กิ่

犬ั่

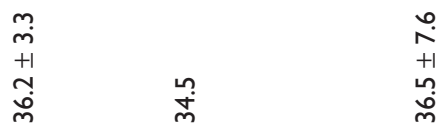

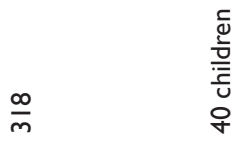

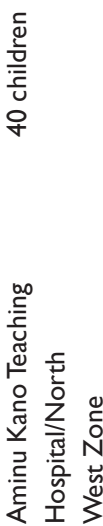

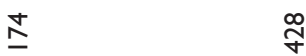

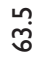

\&

นึำ

กั่

นึำ
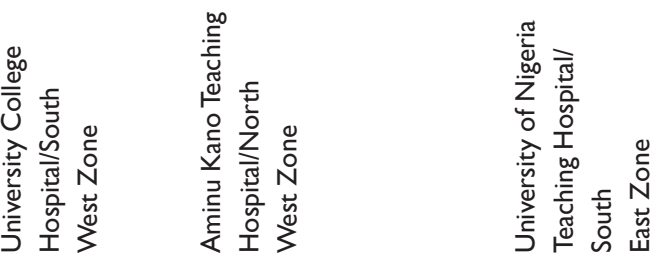

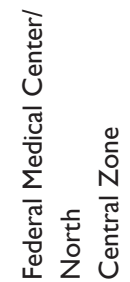

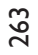

in

으

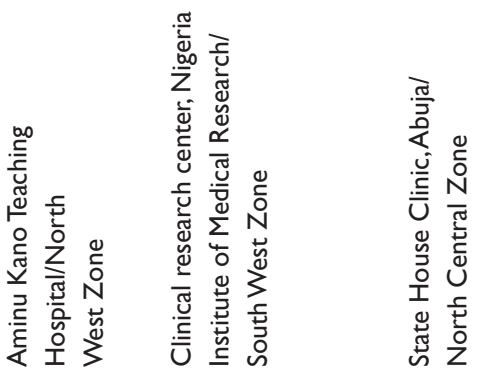
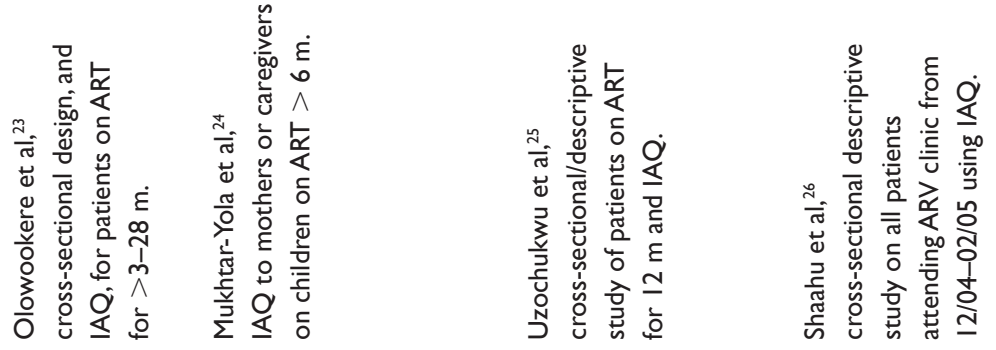

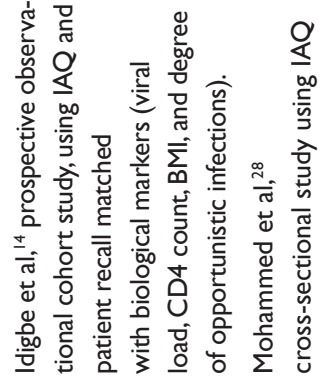


facility as well as the cost of laboratory testing, which can be a huge burden on very poor patients. Therefore poverty is a strong determinant of nonadherence although several specific factors that interplay with poverty may also contribute to poor adherence. For instance, in conflict settings where poverty abounds, studies have shown high adherence to ART, ${ }^{31,32}$ which emphasizes the role of other factors for nonadherence in poverty situations.

The Nigerian national ART program suffered setbacks in 2004 and 2005 due to a shortage of ARV drugs and many patients did not receive their drugs during that period. This structural problem accounted for many cases of nonadherence and patients' dampened morale. This may explain why availability of ARV drugs and pharmacy stock-out were significant reasons for nonadherence in all studies. In addition, this system-induced nonadherence could have promoted the development of drug resistant strains resulting in the worsening of patients' health and the transmission of drug resistant strains in the population.

Globally, stigma and discrimination are major obstacles leading to reduced treatment-seeking behavior ${ }^{33}$ and effective HIV/AIDS prevention and care, ${ }^{34}$ especially in sub-Saharan Africa. Studies show that patients often missed their doses as a result of fear of being identified as HIV-positive and being on ARV medications for the rest of their lives. As a result, strategies to address the problem of stigma should be important and necessary components of all adherencereduction interventions.

Adverse effects of medication and pill burden were also identified as pertinent reasons for nonadherence in these studies. Interestingly, this issue of side effects with ARV drugs was also an important aspect of adherence studies in developed countries. ${ }^{11}$ The adverse effects and pill burden of ARV drugs can compromise the effectiveness of treatment programs, particularly in low and medium income countries. ${ }^{35}$ Therefore, it is important that health care personnel engage in adequate patient counseling about these side effects and their routine management when they do occur. Pill burden can be particularly difficult, especially for less-educated patients. This population may find it difficult to comply with the complex treatment regimen with the resultant forgetfulness leading to nonadherence. In addition, the modification of the treatment regime in predominantly Muslim communities in Nigeria to accommodate changes in eating habits during the Ramadan fasting period was an important innovation in the study by Habib and colleagues. ${ }^{22}$

The introduction of directly observed therapy for antiretroviral therapy (DOT-ART) currently used in tuberculosis programs, has been shown to be acceptable and was associated with good clinical outcome in Haiti. ${ }^{36}$ However, DOT-ART is still controversial because it may not be suitable for life-long combination $\mathrm{ART}^{37}$ and there are mixed results; some studies did not confer significant increases in adherence over self-administered studies. ${ }^{38-40}$ Nevertheless, the one DOT-ART study included in this review ${ }^{19}$ did show a significantly higher adherence rate in the directly observed patients than in the self administered patients.

The effects of sociodemographic factors on adherence have also been analyzed. Some studies have found associations between increased adherence rates and patients who are older, male and/or have a higher income. ${ }^{11,12}$ By contrast, others have found no such associations. ${ }^{11,12}$ This points to a need for more specific studies on the role of sociodemographic factors, particularly educational status, gender and income as they affect adherence in low and middle income countries.

The findings in this review have important implications for government policy and for clinicians. First, the high levels of adherence observed in many of the studies in this review and in other studies done in sub-Saharan Africa should be a call to focus on the maintenance of these high rates. This should be done by increasing access to affordable ART and establishing both a reliable drug supply and distribution network from the pharmacy to the patient. The 'out-of-stock syndrome' issue as it occurred in 2004 and 2005 should never repeat itself. Second, poverty, political conflict, and other biosocial factors that may affect adherence should not be used as a rationale for delaying the expansion of ART in Nigeria. Rather the ART programs should focus on evidence-based research to eliminate the barriers of nonadherence in the different geopolitical zones of the country with their unique characteristics of culture, religion, educational status, and health-seeking behaviors.

The clinicians involved in HIV/AIDS care in Nigeria need to be better educated about the biosocial factors of adherence, the relevance of drug monitoring, viral load, CD4 level estimation, as well as other biological markers that are necessary for positive patient treatment outcomes. Severe weaknesses in the overall drug and biologic markers assessments across various ART centers in Nigeria were revealed in the ART program evaluation done by Ekong and colleagues. ${ }^{41}$ In addition, patient counseling on drug regimen, side effects, and the recognition of the early signs of adverse reactions by patients should be part of the duties of all health care personnel involved in these programs. Likewise, adequate 
management of these drug complications by clinicians should be a part of their continuing education.

\section{Conclusions}

Relevant adherence research studies in Nigeria have been identified and the paucity of pediatric and adolescent adherence studies has been noted. Since Nigeria has a high percentage of PLWHA in the world and HIV/AIDS is now a significant cause of morbidity and mortality in Nigeria, it is imperative that the Nigerian ART program be strengthened. This can be done with better management, increased access to free or heavily subsidized ARV drugs, more evidencedbased research into the biosocial factors affecting adherence to ART, and the implementation of continuous monitoring and evaluation mechanisms for adherence which hold the key to the success of the ART program and the prevention of treatment failures.

\section{Acknowledgement}

The preparation of this manuscript was facilitated by National Institute of Mental Health grant number RO1 MH073361-02.

\section{Disclosures}

The authors report no conflicts of interest in this work.

\section{References}

1. UNAIDS. Report on the global HIV/AIDS epidemic 2008. Geneva Switzerland: UNAIDS: 2008.

2. Arnsten JH, Demas PA, Farzadegan H, et al. Antiretroviral therapy adherence and viral suppression in HIV-infected drug users: comparison of self-report and electronic monitoring. Clin Infect Dis. 2001;33:1417-1423.

3. Peterson GL, Swindells S, Mohr J, et al. Adherence to protease inhibitor therapy and outcome in patients with HIV infection. Ann Intern Med. 2000;133:21-30

4. Gill CJ, Hamer DH, Simon JL, Thea DM, Sabin LL. No room for complacency about adherence to antiretroviral therapy in sub-Saharan Africa. AIDS. 2005;19:1243-1249.

5. Chesney MA. The elusive gold standard: future perspectives for HIV adherence assessment and intervention. J Acquir Immune Defic Syndr. 2006;43 Suppl 1:S3-S9.

6. Lucas GM, Chaisson RE, Moore RD. Highly active antiretroviral therapy in a large urban clinic: risk factors for virologic failure and adverse drug reactions. Ann Intern Med. 1999;131:81-87.

7. Bangsberg DR, Acoata EP, Gupta R, et al. Adherence-resistance relationships for protease and nonnucleoside reverse transcriptase inhibitors explained by virologic fitness. AIDS. 2006;20:223-231

8. Bangsberg DR, Perry S, Charlebios ED, et al. Non-adherence to highly active antiretroviral therapy predicts progression to AIDS. AIDS 2001;15:1181-1183

9. Nachega JB, Hislop M, Dowdy DW, et al. Adherence to highly active antiretroviral therapy assessed by pharmacy claims predicts survival in HIV-infected South African Adults. J Acqui Immune Defic Syndr. 2006;43:78-84.
10. Hogg RS, Heath K, Bangsberg D, et al. Intermittent use of triple-combination therapy is predictive of mortality at baseline and after 1 year of follow-up. AIDS. 2002;16:1051-1058.

11. Mills EJ, Nachega JB, Buchan I, et al. Adherence to antiretroviral therapy in sub-Saharan Africa and North America: A meta-analysis. JAMA. 2006;296(6):679-690.

12. Mills EJ, Nachega JB, Bangsberg DR, Sing S, Rachlis B, et al. Adherence to HAART: A systemic review of developed and developing nation patient-reported barriers and facilitators. PLoS Med. 2006; 3(11):e438.

13. Castro A. Adherence to antiretroviral therapy: merging the clinical and social course of AIDS. PLoS Med. 2005;2(12):e338.

14. Idigbe EO, Adewole TA, Eisen G, et al. Management of HIV-1 infection with combination of Nevirapine, Stavudine, and Lamivudine; a preliminary report on the Nigerian antiretroviral program. J Acquir Immune Defic Syndr. 2005;40(1):65-69.

15. Lambo E. Nigeria has established 74 ARV treatment centers nationwide. HIV/AIDS News. 2006 March 15.

16. WHO. World Health Statistics 2007. Geneva, Switzerland: World Health Organization; 2007.

17. Daniel OJ, Oladapo OT, Ogundahunsi OA, Fagbenro S, Ogun SA, Odusoga OA. Default from antiretroviral treatment program in Sagamu, Nigeria. Afr J Biomed Res. 2008;11:221-224.

18. Erah PO, Arute JE. Adherence of HIV/AIDS patients to antiretroviral therapy in a tertiary health facility in Benin City. Afr J Pharm Pharmacol. 2008;2(7):145-152.

19. Idoko JA, Agbaji O, Agaba P, et al. Direct observation therapy-highly active antiretroviral therapy in a resource-limited setting: the use of community treatment support can be effective. Int J STD AIDS. 2007;18:760-763.

20. Afolabi MO, Ijadunola KT, Fatusi AO, Olasode OA. Determinants of adherence to antiretroviral drugs among people living with HIV/AIDS in the Ife-Ijesa of Osun State, Nigeria. Afr J Prm Health Care Fam Med. 2009:1(1), Art \# 6, 6 pages. DOI:10.4102/phcfm.v1i1.6.

21. Nwauche CA, Erhabor O, Ejele OA, Akani CI. Adherence to antiretroviral therapy among HIV-infected subjects in a resourcelimited setting in the Niger Delta of Nigeria. Afr J Health Sci. 2006;13(3-4):13-17.

22. Habib AG, Shepherd JC, Eng MLK, et al. Adherence to antiretroviral therapy(ART) during Muslim Ramadan fasting. AIDS Behav. 2009;13:42-45.

23. Olowookere SA, Fatiregun AA, Akinyemi JO, Bamgboye AE, Osagbemi GK. Prevalence and determinants of nonadherence to highly active antiretroviral therapy among people living with HIV/AIDS in Ibadan, Nigeria. J Infect Dev Ctries. 2008;2(5): 369-372.

24. Mukhtar-Yola M, Adeleke S, Gwarzo D, Ladan ZF. Preliminary investigation of adherence to antiretroviral therapy among children in Aminu Kano Teaching Hospital, Nigeria. Afr J AIDS Res. 2006;5(2):141-144.

25. Uzochukwu BSC, Onwujekwe OE, Onoka AC, Okoli C, Uguru NP, Chukwuogo OI. Determinants of non-adherence to subsidized anti-retroviral treatment in southeast Nigeria. Health Policy Plan. 2009;24:189-196.

26. Shaahu VN, Lawoyin TO, Sangowawa AO. Adherence to highly active antiretroviral therapy (HAART) at a Federal Medical Center. Afr J Med Sci. 2008;37:29-36.

27. Iliyasu IS, Kabir M, Abubakar IS, Babashani M, Zubair ZA. Compliance to antiretroviral therapy among AIDS patients in Amino Kano Teaxhing Hospital, Kano, Nigeria. Nig J Med. 2005;14(3):290-294.

28. Mohammed MD, Sarki R. Adherence to antiretroviral drugs in NorthCentral zone of Nigeria. East and Central African Journal of Pharmaceutical Sciences. 2004;7(3):52-55.

29. Nachega JB, Mill EJ, Schechter M. Antiretroviral therapy adherence and retention in care in middle-income and low-income countries: current status of knowledge and research priorities. Curr Opin HIV AIDS. 2010;5(1)70-77. 
30. Ware NC, Idoko J, Kanya S, et al. Explaining adherence success in subSaharan Africa: an ethnographic study. PLoS Med. 2009;6(1):e1000011.

31. Culbert H, Tu D, O'Brian DP, et al. HIV treatment in a conflict setting: outcome and experiences from Bukavu, Democratic Republic of the Congo. PLoS Med. 2007;4:e129.

32. Ellman T, Culbert H, Torres-Feced V. Treatment of AIDS in conflict affected settings: a failure of imagination. Lancet. 2006;365:278-280.

33. Valdiseri OR. HIV/AIDS stigma: An impediment to public health. Am J Public Health. 2000;92(3):341-342.

34. Parker R, Aggleton P. HIV and AIDS-related stigma and discrimination: a conceptual framework and implications for action. Soc Sci Med. 2003;57:13-24.

35. UNAID 2008: Report on the global AIDS epidemic: Geneva: UNAIDS 2008. Available from http://www.unaids.org/en/KnowledgeCentre/HIVData/GlobalReport/2008/. Accessed Nov 20, 2009.

36. Farmers P, Leandre F, Mukherjee J, et al. Community-based treatment of advanced HIV disease: introducing DOT-HAART (directly observed therapy with highly active antiretroviral therapy). Bull World Health Org. 2001;79:1145-1151.
37. Lucas GM, Flexner CW, Moore RD. Directly administered antiretroviral therapy in the treatment of HIV infection: benefit or burden? AIDS Patient Care STDS. 2002;16:527-535.

38. Nachega JB, Chaisson RE, Goliath RE, et al. Randomized control trial of trained patient-nominated treatment supporters providing directly observed antiretroviral therapy in HIV infected adults: 16th Conference on Retroviruses and Opportunistic Infections: 2009 Feb 8-11, Montreal, Canada. Abstract no. 143.

39. Wohl AR, Garland WH, Valencia R, et al. A randomized trial of directly administered antiretroviral therapy and adherence case management intervention. Clin Infect Dis. 2006;42:1628-1635.

40. Gross R, Tierney C, Andrade A, et al; AIDS Clinical Trial Group A5073 Study Team. Modified directly observed antiretroviral therapy compared with self-administered therapy in treatment-naïve HIV-1-infected patients: a randomized trial. Arch Intern Med. 2009;169:1224-1232.

41. Ekong E, Akinlade O, Uwah A, Grant-Isibor I. Study of determinants of non-adherence to antiretroviral drug therapy in a resource-limited setting: 9th European AIDS Conference(EACS): 1st EACS resistance and pharmacology workshop: 2003 Oct 25-59, Warsaw, Poland.
HIV/AIDS - Research and Palliative Care

\section{Publish your work in this journal}

HIV/AIDS - Research and Palliative Care is an international, peerreviewed open-access journal focusing on advances in research in HIV, its clinical progression and management options including antiviral treatment, palliative care and public healthcare policies to control viral spread. The journal welcomes original research, basic science,

\section{Dovepress}

clinical \& epidemiological studies, reviews \& evaluations, expert opinion \& commentary, case reports \& extended reports. The manuscript management system is completely online and includes a very quick and fair peer-review system. Visit http://www.dovepress.com/ testimonials.php to read real quotes from published authors. 